\title{
Value-Based Quality Care for Breast Cancer: More Than Guidelines
}

\author{
Nuh Zafer Cantürk' ${ }^{1}$, (1) Bahadır M. Güllüoğlu²
}

${ }^{1}$ Department of General Surgery, Kocaeli University Faculty of Medicine, Kocaeli, Turkey

${ }^{2}$ Department of General Surgery, Marmara University Faculty of Medicine, İstanbul, Turkey

\section{ABSTRACT}

Although guidelines recommend some of the most expensive diagnostic methods and therapies, some patients do have the opportunity to use them, but some others have overused or misused such methods. The cost of cancer care is increasing, but the satisfaction levels of patients and healthcare workers have not increased in line with this rise. Value-based care for cancer, especially breast cancer, should be implemented. For this reason, all unnecessary screening, tests, treatments, and follow-up parameters should be avoided.

Keywords: Cancer, breast, value, quality, cost

Cite this article as: Cantürk NZ, Güllüoğlu BM. Value-Based Quality Care for Breast Cancer: More Than Guidelines. Eur J Breast Health 2021; 17(4): 297-301.

\section{Key Points}

- The satisfaction of patients and doctors increases, the number of patients and disease severity decline.

- Better use of capacity, delivery of services in suitable conditions, balanced distribution of expenses, decreased cycle time and elimination of low-value or no-value care decrease cost.

- Value-based quality is assessed on three main primary parameters for value-based quality: clinical benefit, toxicity, and cost.

- $\quad$ VBQC in breast cancer may be related to the use of genomic testing, screening for early diagnosis, screening for systemic disease, targeted treatment and surveillance tools.

\section{Introduction}

Guidelines and pathways are the shared decision support tools that aid in better clinical decision making. Guidelines may not be appropriate at the bedside, because they incorporate all potential alternatives. In most situations, the aim of clinical pathways is to assist the practicing clinician in selecting the most effective method among the available choices for a particular patient (1). Thus, establishment of a disease-specific multidisciplinary breast cancer team is essential. The inability to form a multidisciplinary team could delay the start of treatment, resulting not only in loss of time but also economic losses, due to inclination toward unnecessary screening and treatments $(2,3)$. Most of the pathways involve some of the most expensive therapies, but the cost of treatment varies. Thus, we have to move toward practicing value-based care, which saves money and does not lead to a rapid increase in the cost of care while maintaining or improving quality standards.

The costs of delivering care are very high and rising at an unacceptable rate (4). Currently, United States health expenditures represent approximately $17 \%$ of its gross national product (GNP), with projections reaching over $20 \%$ of GNP in the not-so-distant future (5). However, all health services still face major problems, such as failure to prevent disease and disability (e.g., detection of breast cancer at stage III or IV), do not have the chance to perform sentinel lymph node biopsy and/or breast-conserving surgery, waste of resources through low-value activity, harm due to overuse even when quality is high, and inequity due to underuse by groups in high need. In addition, challenges are developing due to increasing expectations, increasing need, financial constraints, and climate change (6-9).

The Merriam-Webster Dictionary (2011) defines value as "a fair return or equivalent in goods, services, or money for something exchanged; the monetary worth of something; market price; or the relative worth, utility, or importance" (10). Variability in care delivery and payment systems is apparent at many levels. Even for those with access and ability to pay for care, unacceptable variability exists in the quality, safety,

This study was presented at the MAYMET-ESO Joint Meeting 2014, Kuşadası and International Breast Cancer Conference-BREASTANBUL 2016, İstanbul. 
and effectiveness of care $(11,12)$. Warren Buffet once said, "Price is what you pay. Value is what you get." He means what you get is more important than what you pay (13), and this refers to improving value by reducing unnecessary costs (waste) and increasing efficiency while maintaining or improving healthcare quality. Value can be formulated as outcome achieved divided by the cost.

In healthcare, value is defined as "the health outcome per dollar of cost expended" (14). The cost of cancer care is rising by $15 \%$ each year. This increase has varied causes. One of them is delay in diagnosis and treatments. In our study that evaluated delay times in patients with breast cancer, as a part of a multinational survey, we reported that the mean total delay time was high (13.8 weeks) in Turkey. The system delay time was twice as long than the patient delay time, which called for implementation of nationwide, organized screening programs and comprehensive cancer centers by healthcare providers (15), because cancer care costs are rising faster than overall healthcare expenditure $(16,17)$. High prices of brand name drugs are creating a difficult situation for patients and oncologists, who are inadequately prepared for these challenges. The monthly and median costs of cancer drugs, once approved by the Federal Drug Agency, increased. In the United States, eight of the top ten most expensive drugs, covered by Medicare, are cancer drugs (18).

A value-based health system is needed to improve health insurance and deliver better health care so that patients receive better health care (19). Globally, the cost of cancer care is increasing, but the satisfaction levels of patients, in regard to unnecessary tests, unacceptable waiting time, ineffective treatment, and costs, and health care workers in regard to increased workload, malpractice, and low income, do not increase in a similar fashion (20). The aim of value-based cancer care (VBCC) is to provide consistent and sustainable health for patients, which can be delivered by a sustainable health system. VBCC can be achieved by increasing income through raising the price of per service, increasing the number of patients with expanding indications, and increasing the attractiveness of health delivery, and by decreasing healthcare costs through reducing the number of health care workers but creating better work distributions, work delegations, and decreasing unnecessary tests/treatments with less medical errors. While the satisfaction of patients and doctors increases, the number of patients and disease severity decline. With VBCC, balanced distribution of expenses, better use of capacity, decreased cycle time, delivery of services in suitable conditions, and elimination of low-value or no-value care decrease cost. The elimination of the latter, "Low (no)-value care", can be achieved by avoiding unnecessary tests, follow-up, screening, and treatment. Decreasing or stabilization of costs results in qualitatively increased or stabilized wellness. Better quality of services can be achieved and sustained by using guidelines and pathways. The American Society of Clinical Oncology (ASCO) value in Cancer Care Task Force was established in 2007, which defined the challenges related to the cost of cancer care and developed strategies to address these challenges. The goals of this task force were as follows: increase physicians' education and guidance about cost, increase patients' education and assistance regarding cost, promote high-value medical decision making, and assess the value of cancer care $(21,22)$. The "academy" concept in surgical education has had a considerable influence on good clinical practice for breast care in the last decade. Implementing "academybased" training in all aspects of postgraduate medical education could improve the effectiveness of patient-centered service and outcomebased quality through efficient teaching methods (23). In the spring of 2013, the ASCO Board of Directors engaged in a strategic discussion
"Increasingly, the desired care for oncology patients will be assessed on the value of that care rather than the cost. ASCO defined value and suggested how value should be integrated into treatment decisions." Topics of VBCC can be outlined as follows:

1. Survival, quality of life, adverse events, tumor response, and time to progression.

2. Cost.

3. Aspects of care delivery, such as access, quality, communication, and social equity, and patient-centered attributes, such as compassion, respect, choice, hope, and opportunity for treatment benefit.

4. Opportunity for innovation and future discovery (24).

Value-based quality is assessed on three main primary parameters: (a) clinical benefit, (b) toxicity, and (c) cost. Clinical benefit and toxicity are equal to the "net health benefit score," and cost is integrated to derive an overall value assessment for an oncology regimen. With better conversations for informing patients about individual decisions, healthcare workers including breast surgeons, oncologists, radiologists, and nurses must support and consider individual patient circumstances; explain the best evidence available on a particular treatment's clinical effectiveness, toxicity, and cost; and compare a new treatment with an existing treatment or, if there is no effective therapy, with best supportive care. The aim of value-based quality care (VBQC) includes safety at hospital (patients who receive healthcare must be as safe as at home), effectiveness (avoiding unnecessary and insufficient use of health service), patient-centered service (considering patients' needs, preferences, and culture), timely service (decreasing waiting time for patients and health workers), productive care (decreasing the waste of manpower, equipment, etc.), and equity (decreasing differences owing to race, ethnicity, geographical, and socio-economic conditions). The need to ensure high-quality cancer care, in addition to rising costs with or without improving outcomes but with quality cancer care, varied depending on the countries, hospitals, and relation with the standards or ideal. Some patients cannot receive any beneficial treatment, or some patients have overused or misused unnecessary or harmful therapy. At this point, the "Guidelines or not Guidelines" is debatable. Quality concurs with evidence-based guidelines and measurement to quality. The measurement of diagnostic and therapeutic procedures, which details evidence-based quality indicators for breast cancer managements, is shown in Table 1 (25-27).

The outcomes of VBCC are survival, achieved health status, recovery level, time to recovery, rate of adverse effects, rate of secondary disorders due to treatments, continuity of recovery, and necessity for other procedures. VBQC is categorized into three levels. Level I includes health state and its degree, Level 2 includes duration of recovery and anxiety due to treatment, and Level 3 includes continuity of recovery and long-term effects of treatment (Table 2). Professional organizations have begun to establish guidelines for tests and procedures, the necessity of which should be questioned and discussed. Developing quality measures around these guidelines will be an significant next step (28).

Most importantly, efforts that identify the system, patient, and disease factors that have affected the relationship between quality, cost, and outcomes are critical for developing effective improvement strategies. The VBCC for each patient requires measurement of outcomes and costs. The satisfaction level of the patients and patients' family with 
the use of care pathways, enhancement, and rehabilitation increases with the number of patients. At the same time, the satisfaction level of healthcare workers increases with motivation, and this satisfies the employee/enterprise/health authority (29).

VBQC in breast cancer, such as genomic testing, screening for early diagnosis, screening for systemic disease, targeted treatment, and surveillance tools, can be achieved by implementing the following suggestions:

- Is genomic tumor testing for breast cancer a standard today? Evidence must be followed. During practice, do we have to perform genomic testing? We have to prefer standards of evidence, rather than standards of practice. Unfortunately, there are many examples of standards of practice racing ahead of evidence and these may not add value to patient care and even cause serious harms (30).

- Assuming that individual testing for breast neoplasms is not yet universal, what are the key challenges for making this a standard practice? There is wide variation in the practice of medicine, which has not been explained. Such practices lead to patient harm and failure to realize the full potential of care innovations. Thus, use of these new technologies should be based on evidence (31).

- Breast screening rates have actually decreased among Caucasians in the last decade, remained stable among African Americans, and actually increased significantly among Asians (up to 66\%). Is it realistic to expect attaining higher percentages? What type of focused interventions may help? Higher screening rates can be expected. However, conflicting recommendations put forth over the last several years have created confusion. This does not mean that recommendations should be frozen, but recommendations would gain much greater traction if they were consistent, based on a clear and consistent review of the evidence, and then implemented through reliable methods (32).

- Do you believe that human epidermal growth factor receptor 2 (HER2)-targeted agents can be used in combination in the future? A new development is not an innovation unless it can show its superiority to current treatments and can deliver higher performance and better outcomes at a better cost (33).

Table 1. Most important evidence-based quality indicators for breast cancer management dedicated by the European Society of Mastology

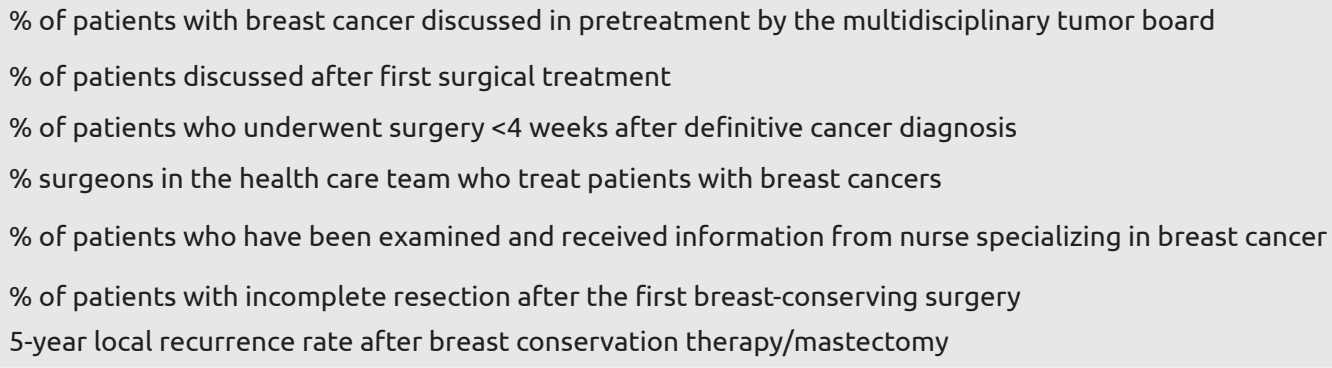

Table 2. Value-based outcome metrics for breast cancer care (27)

\begin{tabular}{|c|c|c|}
\hline \multirow[t]{4}{*}{ Health state } & Expectancy of life & Mortality rate/survival \\
\hline & Health condition & Degree of pain \\
\hline & & Period without disease \\
\hline & & $\begin{array}{l}\text { Performance quality upon return to } \\
\text { work }\end{array}$ \\
\hline \multirow[t]{10}{*}{ Recovery } & Time to recovery & Start of treatment \\
\hline & Inconvenience and anxiety due to treatment & Hospitalization rate \\
\hline & & Delay and anxiety \\
\hline & & Pain during treatment \\
\hline & & Nosocomial infections \\
\hline & & Deep-vein thrombosis \\
\hline & & Time to physical activity and to work \\
\hline & & Redo surgery \\
\hline & & Lack of consciousness \\
\hline & & Medical errors \\
\hline \multirow{6}{*}{$\begin{array}{l}\text { Continuity of } \\
\text { health }\end{array}$} & Continuation of health & Recurrence rate \\
\hline & Long-term effect of treatments & Degree of performance \\
\hline & & Necessity for revisions \\
\hline & & Insufficient rehabilitation \\
\hline & & Results of adverse effect \\
\hline & & Chronic pain \\
\hline
\end{tabular}


- Do you prefer to perform positron emission tomography, computed tomography, and bone scanning in patients with breast cancer at low risk for metastases? Careful history taking and physical examination can help detect symptoms that suggest metastases and signs of locally advanced breast cancer. Decision for imaging studies outside guidelines or clinical trial should be carefully reviewed with the patient and be based on symptoms and physical findings. Non-indicated scans can lead to unnecessary anxiety, testing, and morbidity. In the era of effective adjuvant therapy, micro-metastases are likely to be effectively treated. However, survival improvement in asymptomatic cases with newly identified ductal carcinoma in situ and clinical stage I or stage II breast cancer has not been confirmed by evidence. Thus, patient harm is inevitable (34).

- When is the right time to use surveillance testing, such as serum tumor markers and imaging after curative treatment for breast cancer? Randomized trials have not shown that tumor markers affect survival outcomes. The rate of false-negative or false-positive findings for these markers is still unknown. Thus, the use of these tests can result in false reissuance, increased anxiety, and unnecessary medical evaluation, and then increased cost $(35,36)$.

- At present, some patients have not received any beneficial treatments, but some have overused or misused unnecessary or harmful therapies. Therefore, there is a need to ensure delivery of high-quality cancer care, without increasing the cost of treatments. Measurement of outcomes and costs appears to be a major parameter for VBQC for cancer, including breast cancer. For a successful treatment, satisfaction levels of all including patients, healthcare workers, social insurance companies, and industry and health authority, must be increased.

Peer-review: Externally peer-reviewed.

\section{Authorship Contributions}

Conception: N.Z.C., B.M.G.; Design: N.Z.C.; Supervision: B.M.G.; Data Collection and/or Processing: N.Z.C.; Analysis and/or Interpretation: N.Z.C.; Literature Review: N.Z.C.; Writing: N.Z.C.; Critical Review: B.M.G.

Conflict of Interest: No conflict of interest was declared by the authors.

Financial Disclosure: The authors declared that this study received no financial support.

\section{References}

1. Kuznar W. NCCN Panel addresses value-based care in oncology. Value-Based Cancer Care 2015; 6(3). Available at: https://www. valuebasedcancer.com/issues/2015/april-2015-vol-6-no-3/764-nccnpanel-addresses-value-based-care-in-oncology [Crossref]

2. Güler SA, Cantürk NZ. Multidisciplinary breast cancer teams and proposed standards. Ulus Cerrahi Derg 2014; 31: 39-41. (PMID: 25931943) [Crossref]

3. Pittal Hankal A, Davidson T. Care pathways for patients with breast cancer. Trends Urol Gynaecol Sex Health 2010; 15: 10-13. [Crossref]

4. Lee PV, Berenson RA, Tooker J Payment reform - the need to harmonize approaches in Medicare and the private sector. N Engl J Med 2010; 362: 3-5. (PMID: 20007550) [Crossref]

5. Levin-Scherz J. what drives high health care costs--and how to fight back.
6. Mariotto AB Yabroff KB, Shao Y, Feuer EJ, Brown ML. Projections of the cost of cancer care in the United States: 2010-2020. J Natl Cancer Inst 2011; 103: 117-128. (PMID: 21228314) [Crossref]

7. Feeley TW, Fly HS, Albright H, Walters R, Burke TW. A method for defining value in healthcare using cancer cares a model. J Healthc Manag 2010; 55: 399-411; discussion 411-2. (PMID: 21166323) [Crossref]

8. Rosen R, Curry N, Florin D. Public Views on Choices in Health and Health Care. Available at: https://www.kingsfund.org.uk/sites/default/ files/PublicViewsOnChoices.pdf [Crossref]

9. Wennberg J, McPherson K, Goodman D. Small area analysis and the challenge of practice variation. In: Johnson A, Stukel T, editors. Medical practice variations. health services research. Boston, MA: Springer:2015. [Crossref]

10. Merriam-Webster Dictionary 2011. Available at: https://www. merriamwebster.com/dictionary [Crossref]

11. Kohn LT, Corrigan JM, Donaldson MS, editors. Institute of Medicine (US) committee on quality of health care in america to err is human: building a safer health system. Washington (DC): National Academies Press (US); 2000. [Crossref]

12. Institute of Medicine (US) Committee on Quality of Health Care in America Crossing the Quality Chasm: A New Health System for the 21st CenturyWashington (DC): National Academies Press (US); 2001 (PMID: 25057539) [Crossref]

13. Agency for healthcare research and quality, 2010. Available at: https:// www.ahrq.gov/ [Crossref]

14. Putera I. Redefining health: implication for value based healthcare. Cureus 2017; 9: e1067. (PMID: 28409068) [Crossref]

15. Ozmen V, Boylu S, Ok E, Canturk NZ, Celik V, Kapkac M, et al. Factors affecting breast cancer treatment delay in Turkey: a study from Turkish Federation of Breast Diseases Societies. Eur J Public Health 2015; 25: 9-14. (PMID: 25096257) [Crossref]

16. Shih YC, Ganz PA, Aberle D, Abernethy A, Bekelman J, Brawley O, et al. Delivering high-quality and affordable care throughout the cancer care continuum. J Clin Oncol 2013; 31: 4151-4157. (PMID: 24127450) [Crossref]

17. Wright JD, Neugut AI, Ananth CV, Lewin SN, Wilde ET, Lu Y-S, et al. Deviations from guideline-based therapy for febrile neutropenia in cancer patients and their effect on outcomes. JAMA Intern Med 2013; 173: 559568. (PMID: 23460379) [Crossref]

18. Faden RR, Chalkidou K, Appleby J, Waters HR, Leider JP. Expensive cancer drugs: a comparison between the United States and the United Kingdom. Milbank Q 2009; 87: 789-819. (PMID: 20021586) [Crossref]

19. OECD Reviews of Health Care Quality TURKEY, 2014. Available at: https://www.oecd.org/turkey/oecd-reviews-of-health-care-quality-turkey2013-9789264202054-en.htm [Crossref]

20. Dugdale DC, Epstein R, Pantilat SZ. Time and the patient-physician relationship. J Gen Intern Med 1999; 14(Suppl 1): S34-S40. (PMID: 9933493) [Crossref]

21. ASCO News \& analysis. https://www.asco.org/practice-policy/ policy-issues-statements/asco-in-action/asco-action-brief-valuecancer care\#:-:text=In\%202007\%2C\%20ASCO\%20established $\% 20$ the,quality\%2C\%20and\%20value\%20in\%20concert. [Crossref]

22. Meropol NJ, Schrag D, Smith TJ, Mulvey TM, Langdon RM, Blum D, et al. American Society of Clinical Oncology Guidance Statement: the cost of cancer care. J Clin Oncol 2009; 27: 3868-3874. (PMID: 19581533) [Crossref]

23. Yilmaz OC, Cantürk NZ, Kebudi A, Güler SA, Erkek A, Rezai M, et al. The emerging role of national academies in surgical training: an inspiring environment for increasing the quality of health care in breast cancer management. J Cancer Educ 2014; 29: 395-400. (PMID: 24515563) [Crossref] 
24. Schickedanz AD, Schillinger D, Landefeld CS, Knight SJ, Williams BA, Sudore RL. A clinical framework for improving the advance care planning process: start with patients' self-identified barriers J Am Geriatr Soc 2009; 57: 31-39. (PMID: 19170789) [Crossref]

25. Schnipper LE, Davidson NE, Wollins Ds, Tyne C, Blayney DW, Blum D, et al. American Society of Clinical Oncology statement: a conceptual framework to assess the value of cancer treatment options. J Clin Oncol 2015; 33: 2563-2577. (PMID: 26101248) [Crossref]

26. Lemieux J, Audet $S$. Value assessment in oncology drugs: funding of drugs for metastatic breast cancer in Canada. Curr Oncol 2018; 25: S161-S170. (PMID: 29910659) [Crossref]

27. Biganzoli L, Marotti L, Hart CD, Cataliotti L, Cutuli B, Kuhn T, et al. Quality indicators in breast cancer care: an update from the EUSOMA working group. Eur J Cancer 2017; 86: 59-81. (PMID: 28963914) [Crossref]

28. Fayanju OM, MayoTl, Spinks TE, Lee, S, Bercenas CH, Smith BD, et al. Value-based breast cancer care: a multidisciplinary approach for defining patient centered outcomes. Ann Surg Oncol 2016; 23: 2385-2390. (PMID: 26979306) [Crossref]

29. Mosadeghrad AM. Factors affecting medical service quality. Iran J Public Health 2014; 43: 210-220. (PMID: 26060745) [Crossref]
30. Costa RLB, Gradishar WJ. Do genomic assays provide the necessary confidence to de-escalate adjuvant therapy? J Clin Oncol 2018; 36: 725727. (PMID: 29373092)

31. Sepucha KR, Belkora J. Importance of decision quality in breast cancer care. Psicooncologia 2010; 7:313-328. [Crossref]

32. Gathirua-Mwangi WG, Monahan PO, Stump T, Rawl SM, Skinner C, Champion VL. Mammography adherence in African American Women: results of a randomized controlled. J Ann Behav Med 2016; 50: 70-78. (PMID: 26416127) [Crossref]

33. Nixon N, Verma S. A value based approach to treatment of HER-2 positive breast cancer. ASCO Educational Book 2016: e56-63. [Crossref]

34. Yang SK, Cho N, Moon WK. The role of PET/CT for evaluating breast cancer. Korean J Radiol 2007; 8: 429-437. (PMID: 17923786) [Crossref]

35. Smith TJ. Breast cancer surveillance guidelines. J Oncol Pract 2013; 9: 65-67.

36. Rojas MP, Telaro E, Russo A, et al. Follow-up strategies for women treated for early breast cancer. Cochrane Database Syst Rev 2005;CD001768. (PMID: 15674884) [Crossref] 